\title{
A Novel Role for the Calcium Sensing Receptor in Rat Diabetic Encephalopathy
}

\author{
Shiyun Donga Gang Li ${ }^{\mathrm{b}}$ Dan Zheng ${ }^{\mathrm{a}}$ Jichao Wu Dianjun Sun ${ }^{\mathrm{a}}$ Fan Yang ${ }^{\mathrm{a}}$ \\ Xiangjing $\mathrm{Yu}^{\mathrm{c}}$ Ting $\mathrm{Li}^{\mathrm{a}}$ Aili Sun ${ }^{\mathrm{a}}$ Jiaqi Liu ${ }^{\mathrm{a}}$ Xin Zhong ${ }^{\mathrm{a}}$ Changqing X $\mathrm{u}^{\mathrm{a}, \mathrm{d}}$ \\ Fanghao Lu $^{\mathrm{a}}$ Weihua Zhanga,d
}

aDepartment of Pathophysiology, Harbin Medical University, ${ }^{b}$ Department of General Surgery, the second affiliated Hospital of Harbin Medical University, 'Clinical laboratory, Harbin Medical University Cancer Hospital, 'Bio-Pharmaceutical Key Laboratory of Heilongjiang Province, ${ }^{e}$ Center for Endemic Disease Control, Chinese Center for Disease Control and Prevention, Harbin Medical University, Harbin, China

\section{Key Words}

Calcium sensing receptor $\bullet$ Diabetic encephalopathy $\bullet\left[\mathrm{Ca}^{2+}\right]_{i} \cdot$ High glucose

\begin{abstract}
Background: Diabetic encephalopathy is a common complication of diabetes, and it may be involved in altering intracellular calcium concentrations $\left(\left[\mathrm{Ca}^{2+}\right]\right.$.) at its onset. The calcium sensing receptor (CaSR) is a G-protein coupled receptor, however, the functional involvement of CaSR in diabetic encephalopathy remains unclear. Methods: In this study, diabetic rats were modeled by STZ $(50 \mathrm{mg} / \mathrm{kg})$. At the end of 4, 8 and 12 weeks, the CaSR expression in hippocampus was analyzed by Western blot. In neonatal rat hippocampal neurons, the $\left[\mathrm{Ca}^{2+}\right]$, was detected by laser scanning confocal microscopy, the production of reactive oxygen species (ROS) in mitochondria, the level of $\mathrm{NO}$ and the mitochondrial transmembrane potential were measured by MitoSOX, DAF-FM and JC-1, respectively. Results: Our results showed in hippocampal neurons treated with high glucose, CaSR regulated $\left[\mathrm{Ca}^{2+}\right]_{i}$ through the PLC-IP3 pathway. CaSR expression was decreased and was involved in the changes in $\left[\mathrm{Ca}^{2+}\right]_{i .}$. Mitochondrial membrane potential, NO release and expression of p-eNOS decreased, while the production of ROS in mitochondria increased. Conclusion: Down-regulation of CaSR expression was accompanied by neuronal injury, calcium disturbance, increased ROS production and decreased release of NO. Up-regulation of CaSR expression attenuated these changes through a positive compensatory protective mechanism to inhibit and delay diabetic encephalopathy in rats.
\end{abstract}

Shiyun Dong and Gang Li equally contributed to this study. 


\section{Cellular Physiology and Biochemistry}

Cell Physiol Biochem 2015;35:38-50

\begin{tabular}{l|l}
\hline DOI: $10.1159 / 000369673$ & (c) 2015 S. Karger AG, Basel
\end{tabular}

www.karger.com/cpb

\section{Introduction}

Diabetes and its associated complications, such as diabetic cardiomyopathy, diabetic nephropathy, and peripheral arterial disease, are known as major health disorders. The epidemic of obesity as well as sedentary lifestyles are projected to result in over 300 million people with diabetes by 2025 [1]. Diabetes increases the risk of nervous system morbidity and mortality. In the last decade, mounting evidence has indicated that type 1 diabetes has adverse effects on central nervous system (CNS) function and cognition [2].

Diabetic encephalopathy was first proposed by Nielsen [3] as a diabetic complication and was associated with cognitive deficits and an increased risk of dementia, particularly in the elderly. Cognitive dysfunction in diabetes is characterized by lowered performance in several cognitive domains, especially slowing of mental speed and diminished flexibility. Studies of streptozotocin (STZ)-induced diabetes in rats have demonstrated neurobehavioral deficits using the Morris water maze, which is associated with impaired hippocampal long-term potentiation [4]. The multifaceted pathogenesis of diabetic encephalopathy is not yet completely understood, but classical factors such as an imbalance in $\mathrm{Ca}^{2+}$ homeostasis [5] may contribute to the pathology of diabetic encephalopathy. In the CNS, $\mathrm{Ca}^{2+}$ acts as a second messenger and is known to be associated with almost every cellular event, including ion channel function, cellular proliferation and migration, neurotransmitter secretion, axon pathfinding, and dendritic outgrowth. Therefore, the alterations in $\left[\mathrm{Ca}^{2+}\right]_{\mathrm{i}}$ affect the execution of $\mathrm{Ca}^{2+}$-dependentfunctions. Oxidative stress is also considered to regulate the pathogenesis of diabetic encephalopathy. The brain is especially vulnerable to oxidative damage as a result of its high oxygen consumption rate. Under normal physiological conditions, a balance exists between the production of ROS and antioxidant mechanisms in the CNS. Toxic $\mathrm{O}_{2}^{-}$and $\mathrm{OH}^{-}$radicals have been implicated in diabetes because they cause non-specific glycation of proteins, peroxidation of membrane lipids and protein cross-linking, causing loss of organelle function and cell death [6].

$\mathrm{Ca}^{2+}$ and ROS are involved in the response to diabetic encephalopathy. However, it is still not clear how these two compounds play roles in diabetic encephalopathy. In addition, it has been clearly proven that both ROS and $\mathrm{Ca}^{2+}$ signals are intimately interconnected, as sub-micromolar concentrations of $\mathrm{Ca}^{2+}$ stimulate ROS production by mitochondria [7]. This might be significant in de-energized mitochondria in vivo, which are unable to take up $\mathrm{Ca}^{2+}$ and to control the cytosolic $\mathrm{Ca}^{2+}$ concentration. The mechanisms of the harmful effects of $\mathrm{Ca}^{2+}$ on mitochondria are generally assumed to involve high $\mathrm{Ca}^{2+}$ loads and excessive ROS generation. However, data available from in vitro studies are very contradictory as to the effect of $\mathrm{Ca}^{2+}$ on mitochondrial ROS generation [8].

The calcium-sensing receptor (CaSR) is a member of the G protein-coupled receptor (GPCR) superfamily [9]. CaSR has been localized to almost all areas of the brain, including the hippocampus [10]. As a GPCR, CaSR activation stimulates phospholipase to generate diacylglycerol (DAG) and inositol triphosphate $\left(\mathrm{IP}_{3}\right) . \mathrm{IP}_{3}$ can trigger the release of calcium from internal stores while DAG activates protein kinases C (PKC) [11].

CaSR has been implicated in a variety of functions in neurons, including neuronal growth, synaptic plasticity, migration, differentiation, injury, neurotransmission and neurodegeneration with long-term memory loss in Alzheimer's disease [12-14]. However, the potential role of CaSR in the progress of diabetic encephalopathy has not been examined.

Neurons are highly specialized for the processing and transmission of cellular signals; they communicate with one another via synapses, where the axon terminal of one cell impinges upon another neuron's dendrite, soma or, less commonly, axon. CaSR has been implicated in neuronal growth, as activation of CaSR in late fetal sympathetic neurons promoted axonal growth, whereas CaSR-deficient or deleted mice failed to exhibit such a change [12].

In this study, we demonstrated that CaSR regulated $\left[\mathrm{Ca}^{2+}\right]_{i}$ and identified its mechanism in hippocampal neurons incubated with high glucose concentrations. 


\section{Cellular Physiology

Cell Physiol Biochem 2015;35:38-50

\section{Materials and Methods}

Animals

Male Wistar rats (200-250 g) were purchased from Harbin Medical University (Heilongjiang, China). All Wistar rats were 12-16 weeks old. All animal protocols were approved by the Animal Care and Use Committee of Harbin Medical University.

\section{Diabetes model and treatment protocols}

Diabetes was induced in rats by tail vein injection of streptozotocin (STZ, $50 \mathrm{mg} / \mathrm{kg}$ ) dissolved in $0.1 \mathrm{M}$ citrate buffer ( $\mathrm{pH} 4.5$ ), whereas the control group was injected with citrate buffer alone by the same route. Blood glucose levels were measured using blood glucose test strips $72 \mathrm{~h}$ after STZ injection, and blood glucose levels over $16.7 \mathrm{mmol} / \mathrm{L}$ were considered to indicate diabetes. Wistar rats were randomly divided into 4 groups including control, diabetic- 4 weeks (Dia-4W), diabetic- 8 weeks (Dia-8W) and diabetic-12 weeks (Dia-12W). Blood glucose measurements were repeated after 2 weeks of treatment in each group.

\section{Cell culture and preparation}

Primary cultures of neonatal rat hippocampal neurons were prepared by previously described methods [15]. Briefly, early postnatal rats were decapitated, and the brains dissected from the skull and then transferred into a Petri dish with pre-cooled D-Hanks solution. Brains were cut along the midline, and the hippocampus was extracted from each hemisphere. Hippocampi were incubated in solution of $0.125 \% \mathrm{cru}$ de trypsin $(1.5 \mathrm{ml})$ for 20 minutes at $37^{\circ} \mathrm{C}$. This solution was replaced with a $0.125 \%$ solution of crude trypsin with Trypsin inhibitor and was incubated for 5 minutes at room temperature. Cells were centrifuged at $1000 \mathrm{r} / \mathrm{min}$ for 10 minutes, and then, hippocampi were cultured as monolayers at a density of $4-5 \times 10^{6}$ cells $/ \mathrm{cm}^{2}$ in neurobasal medium (Gibco) supplemented with $2 \%$ B-27 and $2 \mathrm{mM}$ glutamine in humidified incubator $\left(5 \% \mathrm{CO}_{2}\right.$ at $\left.37^{\circ} \mathrm{C}\right)$.

Neonatal rat hippocampal neurons were randomly divided into the following treatment groups: control (low glucose, $5.5 \mathrm{mM}$ ), high glucose (HG, $30.0 \mathrm{mM}$ ), HG + Calindol (2 $\mu \mathrm{M}$, a CaSR activator), HG+ Calhex231 (3 $\mu \mathrm{M}$, a CaSR inhibitor), $\mathrm{HG}+\mathrm{CaCl}_{2}(2.3 \mathrm{mM}), \mathrm{HG}+$ IBMX $(100 \mu \mathrm{M}, 3$-isobutyl-1-methylxanthine, a phosphodiesterase (PDE) inhibitor), and HG + L-NMMA (100 $\mu \mathrm{M}$, a nitric oxide synthase inhibitor). Drugs were dissolved in pre-warmed medium and added directly to the culture for 48 or72 hours.

\section{Neonatal rat hippocampal neurons loaded with Fluo-4 AM}

$\left[\mathrm{Ca}^{2+}\right]_{\mathrm{i}}$ were determined as previously described $[16,17]$. In brief, neurons were plated on poly-Llysine-coated $15 \mathrm{~mm}$ glass coverslips at a density of 5,000 cells per coverslip. On the day of imaging, neurons were washed twice with normal saline solution (NSS: $137 \mathrm{mM} \mathrm{NaCl}, 25 \mathrm{mM}$ Glucose, $10 \mathrm{mM}$ HEPES, $5 \mathrm{mM}$ $\mathrm{KCl}, 1 \mathrm{mM} \mathrm{MgCl}_{2}$, and $2 \mathrm{mM} \mathrm{CaCl}_{2}$ at $\mathrm{pH}$ 7.4).

The washed neurons were then labeled with $5 \mu \mathrm{M}$ Fluo- 4 AM to measure $\left[\mathrm{Ca}^{2+}\right]_{\mathrm{i}}$ for $30 \mathrm{~min}$ at $37^{\circ} \mathrm{C}$. The neurons were washed twice with NSS and left at $37^{\circ} \mathrm{C}$ for another $30 \mathrm{~min}$ to allow for complete hydrolysis of the acetoxymethyl (AM) ester moiety, during which time the cells were treated with pipette-applied U73122 (PLC inhibitor, $10 \mu \mathrm{M}$ ), 2-APB (IP ${ }_{3} \mathrm{R}$ inhibitor, $75 \mu \mathrm{M}$ ), Calhex231, MK801 (NMDA receptor inhibitor, $10 \mu \mathrm{M}$ ), or $\mathrm{CdCl}_{2}$ (calcium channel inhibitor, $0.2 \mathrm{mM}$ ). The neurons were then exposed to Calindol, and the fluorescence measurement of $\mathrm{Ca}^{2+}$ was captured using a laser scanning confocal microscope (Leica Microsystems, Wetzlar, Germany) at an excitation wavelength of $488 \mathrm{~nm}$ and an emission wavelength of $530 \mathrm{~nm}$ for $\left[\mathrm{Ca}^{2+}\right]_{\mathrm{i}^{*}}$

\section{Mitochondrial ROS production}

Mitochondrial ROS production was measured using MitoSOX Red [18]. Single rat hippocampi were loaded with $5 \mu \mathrm{mol} / \mathrm{L}$ MitoSOX Red at room temperature for $15 \mathrm{~min}$. MitoSOX Red fluorescence was measured at $583 \mathrm{~nm}$ following excitation at $488 \mathrm{~nm}$ using a Zeiss LSM 510 inverted confocal microscope.

\section{Analysis of mitochondrial transmembrane potential}

Treated neurons ( $48 \mathrm{~h}$ ) were washed with cold PBS and stained with JC-1 (4 $\mu \mathrm{g} / \mathrm{ml}$, Molecular Probes) for $15 \mathrm{~min}$ at $37^{\circ} \mathrm{C}$ in the dark. The data were acquired using a Zeiss LSM 510 inverted confocal microscope measuring the levels of green and red fluorescence at 514/529 (FL-1) and 585/590 nm (FL-2), respectively. 
Cell Physiol Biochem 2015;35:38-50

\begin{tabular}{l|l}
\hline DOI: $10.1159 / 000369673$ & (c) 2015 S. Karger AG, Basel
\end{tabular}

\begin{tabular}{l|l} 
Publisned online: January 02, 2015 & www.karger.com/cpb \\
\hline
\end{tabular}

Dong et al.: CaSR in Diabetic Encephalopathy

NO detection by fluorescence

The fluorescent probe DAF-FM (Merck, Darmstadt, Germany) was used to detect intracellular NO [19]. Treated neurons (48 h) were washed with cold PBS and supplemented with $10 \mu \mathrm{M}$ DAF-FM for 30 min at $37^{\circ} \mathrm{C}$. DAF-FM fluorescence was excited at a wavelength of $480 \mathrm{~nm}$, while emission was detected with an emission filter of $527 \mathrm{~nm}$.

Statistical analysis

Data are expressed as the mean \pm S.E.M. All data involving multiple groups were analyzed by one-way ANOVA. Differences between individual groups were analyzed using Student's $t$-test. $P<0.05$ was considered statistically significant.

\section{Results}

General features of experimental rats

Some evidence demonstrates that defective adult neurogenesis is present in individuals with diabetes. However, the mechanisms related to depression and cognitive dysfunction in patients with diabetes have not been elucidated. In our study, a type 1 diabetes model was established by intraperitoneal injection of STZ. Compared with the control group, water and food intake and the concentration of glucose were significantly increased in the diabetes groups (Fig. 1a). These results suggested that the type 1 diabetes model was successfully established.

Ultrastructural changes in the hippocampus of diabetic rats viewed by transmission electron microscopy and the apoptotic rate of the diabetic hippocampal neurons examined by TUNEL

Using transmission electron microscopy, we showed that sections of rat hippocampus in the control group had normal structures, nuclear chromatin was rich, and there was abundant rough endoplasmic reticulum. Synaptic structure was clear, and the mitochondria were typically intact. In the dia-4 w group, the hippocampal morphological structure was damaged, the neurons arranged loosely, degenerative diseases occurred, the mitochondria were swollen and slightly disrupted. However, small vessel architecture was intact, and a minority of synapses were mixed together and fused. With the progression of diabetes, pathological changes gradually became more obvious. In the dia-12 w group, obvious swelling, vacuolating and disruption of mitochondria were observed, and a large number of synapses were destroyed (Fig. 1c). To confirm that diabetes results in apoptosis of hippocampal neurons, we examined apoptosis using the TUNEL assay in hippocampus. The number of TUNEL-positive hippocampal neurons was low in the control group. The percentages of apoptotic cells in the dia- $4 \mathrm{w}$, the dia- $8 \mathrm{w}$ and the dia-12 $\mathrm{w}$ groups were increased relative to the control group (Fig. 1b).

Measurement of CaSR levels in the rat hippocampus and hippocampal neurons, as detected by Western blot

CaSR is substantially expressed within the hippocampus [20] and has been implicated in a variety of functions in neurons. In our study, the expression of CaSR in the rat hippocampus was detected by Western blot (Fig. 2a). The CaSR protein content in the hippocampus of rats in the dia- $4 \mathrm{w}$, dia- $8 \mathrm{w}$ and dia-12 $\mathrm{w}$ groups were decreased compared to the control group $(P<0.05)$. These results showed that the expression of CaSR was decreased in the hippocampus of diabetic rats.

To further confirm the role of CaSR in hippocampus of diabetic rats, cultured neonatal rat hippocampal neurons were treated with $30 \mathrm{mM}$ glucose to mimic cellular diabetic encephalopathy. The levels of CaSR protein were detected by Western blot (Fig. 2b). The CaSR protein content in HG group was decreased compared to the control group $(P<0.05)$. CaSR protein levels in the $\mathrm{HG}+$ Calindol group were increased compared to the HG group $(P<0.05)$, 


\section{Cellular Physiology and Biochemistry}

Cell Physiol Biochem 2015;35:38-50

DOI: 10.1159/000369673

Dong et al.: CaSR in Diabetic Encephalopathy

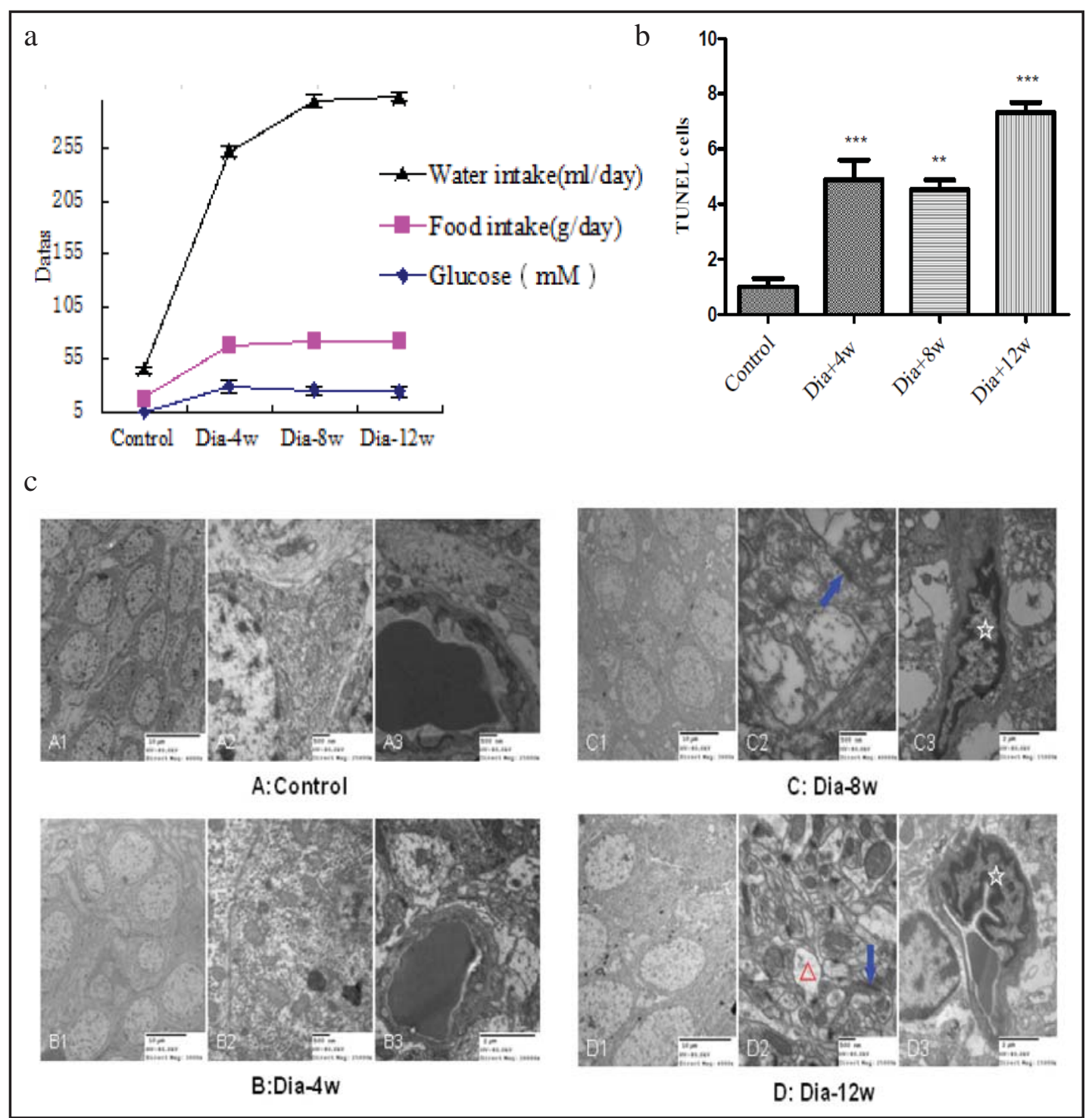

Fig. 1. (a). General characteristics of control and diabetic rats. (b). Representative image of TUNEL staining in the hippocampus of diabetic rats. Quantitation of TUNEL staining for the different groups is shown. Values represent group means \pm SEMs. ${ }^{* *} P<0.01$ vs. Control group, ${ }^{* * *} P<0.001$ vs. Control group. (c). Ultrastructural alterations in rat hippocampus in the different groups. " $\downarrow$ ”indicated apoptosis; “ $\Delta$ "indicated mitochondrion damage;" $\rightarrow$ "indicated synapsis damage.(A) Control group, (A1: 4000X; A2: 25,000X; A3: 25,000X). (B) Dia-4 W group, (B1: 4000X; B2: 25,000X; B3: 20,000X). (C) Dia-8 W group, (C1: 4000X; C2: 40,000X; C3: 15,000X). (D) Dia-12 W group, (D1: 4000X; D2: 25,000X; D3: 15,000X).

while CaSR levels in the HG+Calhex231 group were decreased $(P<0.05)$. These results demonstrated that Calindol could up-regulate the expression of CaSR, while Calhex231 could down-regulate the expression of CaSR.

Measurement of $\left[\mathrm{Ca}^{2+}\right]_{i}$ by laser confocal microscopy

$\mathrm{Ca}^{2+}$ plays an important role in regulating nuclear functions, including cell growth, and death. Our results revealed that Calindol increased the $\left[\mathrm{Ca}^{2+}\right]_{\mathrm{i}}$. Pretreated with Calhex231, U73122 and 2-APB, Calindol couldn't increase the $\left[\mathrm{Ca}^{2+}\right]_{\mathrm{i}}$, the basal $\left[\mathrm{Ca}^{2+}\right]_{\mathrm{i}}$ and the amplitude of $\mathrm{Ca}^{2+}$ transients remained unchanged. These results indicated that hippocampal neurons could regulate $\left[\mathrm{Ca}^{2+}\right]_{\mathrm{i}}$ via the CaSR-PLC-IP ${ }_{3}$ pathway. However, compared to the control group, $\left[\mathrm{Ca}^{2+}\right]_{\mathrm{i}}$ was significantly decreased (Fig. 2c,2d). 


\section{Cellular Physiology Cell Physiol Biochem 2015;35:38-50 \\ \begin{tabular}{l|l} 
DOI: 10.1159/000369673 & O 2015 S. Karger AG, Basel
\end{tabular} \\ and Biochemistry Publisnea onine: January 02, $2015 \quad$ www.karger.com/cpb

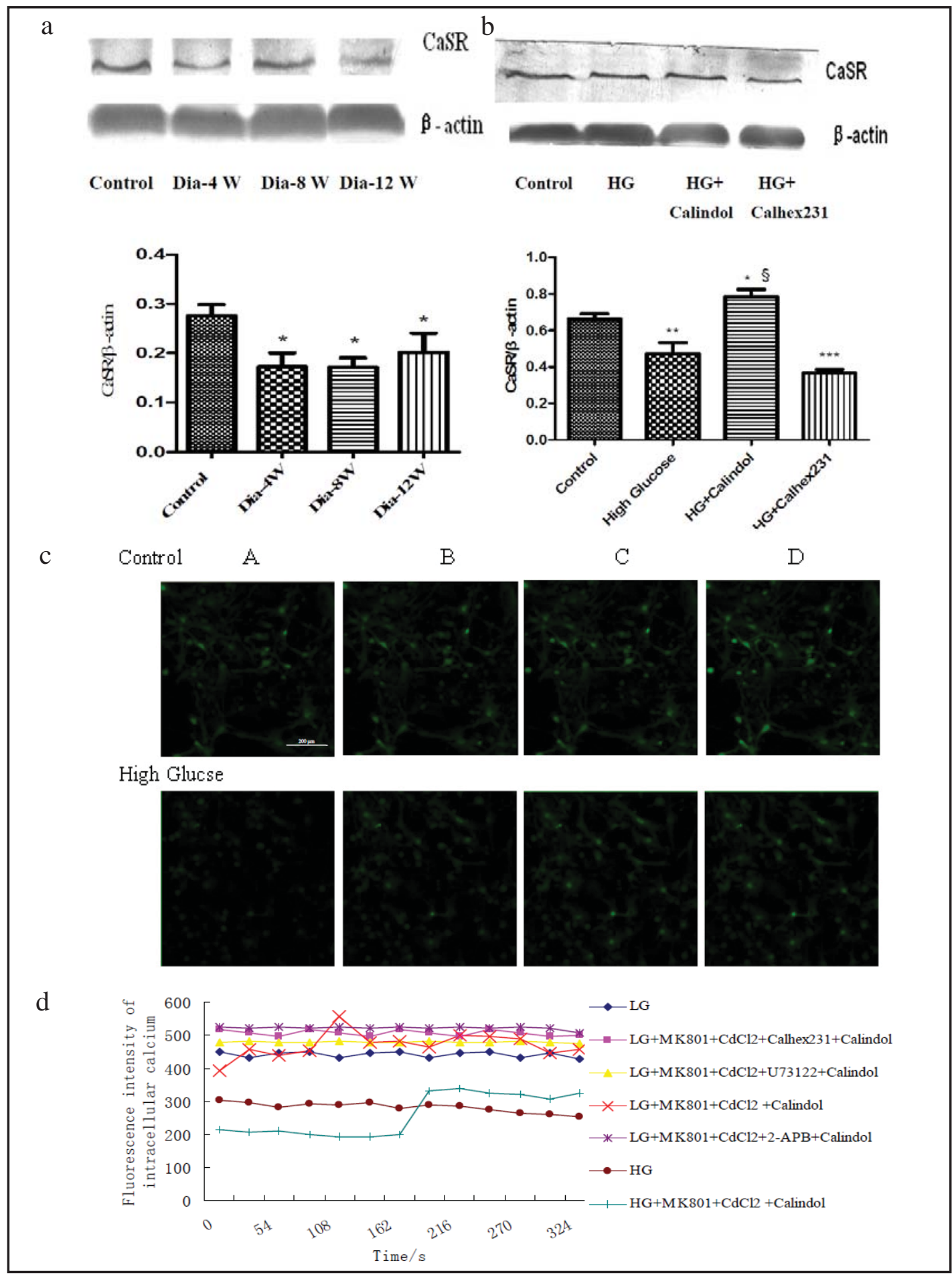

Fig. 2. (a) Protein levels of CaSR in the hippocampus were analyzed by Western blot. Basal levels of CaSR were detected in the control group, which served as the baseline for computing the fold increase for the other groups. The quantitation of the Western blot analyses for CaSR is shown in the lower panel. The fold change values represent group means \pm SEMs. ${ }^{*} P<0.05 v$. Control. (b) Protein levels of CaSR in hippocampal neurons were analyzed by Western blot. Basal levels of CaSR were detected in the control group, which served as the baseline for computing the fold increase for the other groups. The quantitation of the Western blot analyses for CaSR is shown in the lower panel. The fold change values represent group means \pm SEMs.* $P<0.05$ vs. Control; ${ }^{* *} P<0.01$ vs. Control; ${ }^{* * *} P<0.001$ vs. Control; $§ P<0.001$ vs. HG group. (c) Changes in the 


\section{Cellular Physiology and Biochemistry}

Cell Physiol Biochem 2015;35:38-50

DOI: $10.1159 / 000369673$

Dong et al.: CaSR in Diabetic Encephalopathy

$\mathrm{Ca}^{2+}$ gradient in hippocampal neurons was detected by laser scanning confocal microscopy with Fluo-4AM staining. Fluorescence images in A, B, C and D represent 0 s, 30 s, 180 s and 300 s, respectively. Scale bar is $200 \mu \mathrm{m}$. (d) The changes in fluorescence intensities of intracellular calcium were recorded continuously with laser scanning confocal microscopy for each of the different treatments. Intracellular calcium was recorded after $48 \mathrm{~h}$ of high glucose incubation.

Fig. 3 Protein levels of p-CaMKII/ CaMKII in the hippocampus were analyzed by Western blot. Basal levels of p-CaMKII/CaMKII were detected in the control group, which served as the baseline for computing the fold increase for the other groups. The quantitation of the Western blot analysis for $\mathrm{p}$ CaMKII/CaMKII is shown in the lower panel. The fold change values represent group means \pm SEMs. * $P<0.05$ vs. control; $\S P<0.05$ vs. HG group.

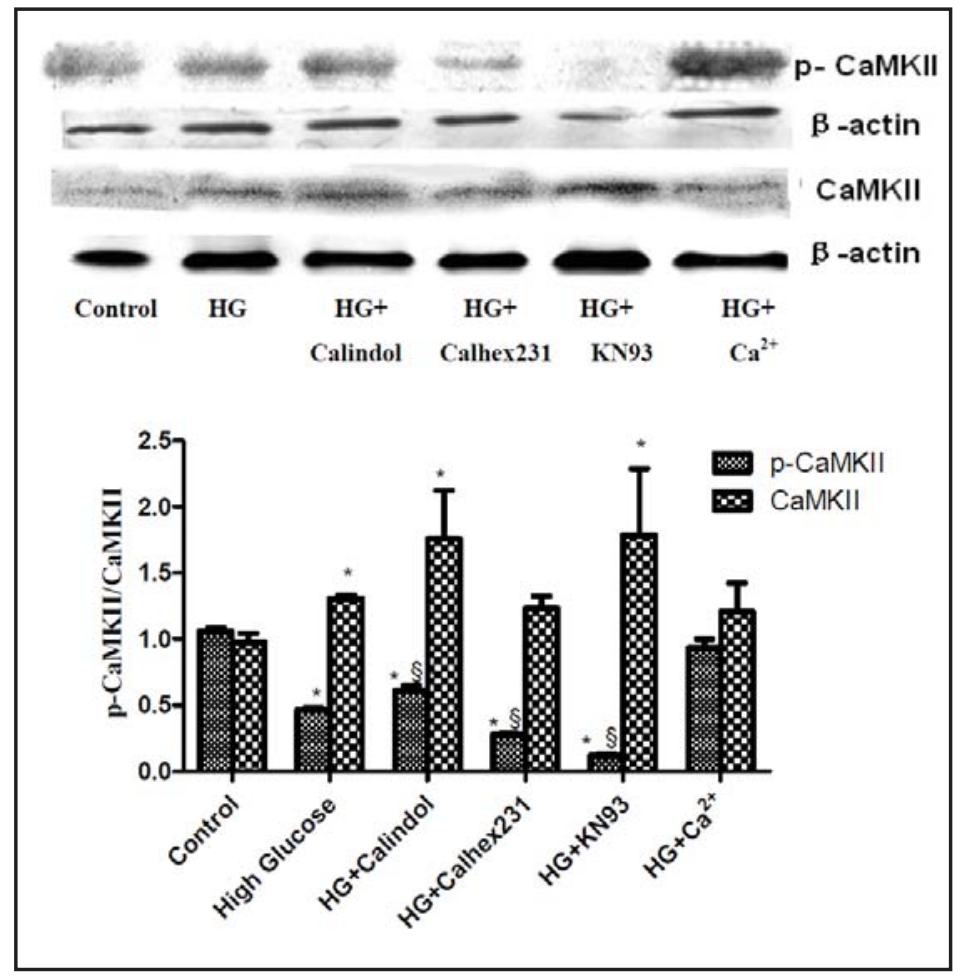

Measurement of p-CaMKII and CaMKII levels in hippocampal neurons by Western blot

Calmodulin-dependent kinase (CaMKII)plays a critical role in mediating calcium-induced dendritic growth in cortical neurons [21]. The levels of phosphorylated CaMKII (pCaMKII) and total CaMKII protein in hippocampal neurons were analyzed by Western blot. The data showed that the levels of p-CaMKII in the HG, HG+Calindol, HG+Calhex231 and $\mathrm{HG}+\mathrm{KN} 93$ groups were decreased compared to the control group $(P<0.05)$. Compared to the HG group, the p-CaMKII levels were increased in the HG+Calindol group and decreased in the $\mathrm{HG}+\mathrm{Calhex231}$ and $\mathrm{HG}+\mathrm{KN} 93$ groups $(P<0.05)$. Compared to the control group,the level of total CaMKII in the HG, HG+Calindol and $\mathrm{HG}+\mathrm{KN} 93$ groups were increased $(P<0.05)$. The levels of p-CaMKII and CaMKII in hippocampal neurons from the $\mathrm{CaCl}_{2}$ group remained nearly unchanged (Fig. 3).

NO release detection by fluorescence and p-eNOS measurement by Western blot

$\mathrm{NO}$ is an essential gas messenger in diverse neural processes such as the regulation of dendrite and dendritic spine morphologies [22, 23]. Fluorescence was utilized to detect NO generation in hippocampal neurons (Fig. 4a). Compared with the control group, the NO fluorescence intensity was lower in the HG, HG+Calhex231 and HG+L-NMMA groups $(P<0.05)$. In contrast, the $\mathrm{HG}+\mathrm{Calindol}$ group and the $\mathrm{HG}+\mathrm{CaCl}_{2}$ group had increased levels of NO compared to the control group and the HG group $(P<0.05)$. The levels of phosphorylated eNOS (peNOS) in hippocampal neurons were analyzed by Western blot, which showed that p-eNOS levels in the HG group were decreased compared to the control group $(P<0.05)$. Compared with the HG group, the expression of p-eNOS in the $\mathrm{HG}+\mathrm{Calindol}$ group and the $\mathrm{CaCl}_{2}$ group were increased, while the p-eNOS protein content of the HG+Calhex231 group and the LNMMA group were decreased $(P<0.01)$ (Fig. 4b). 


\section{Cellular Physiology $\quad$ Cell Physiol Biochem 2015;35:38-50 \\ \begin{tabular}{l|l|l} 
and Biochemistry & $\begin{array}{l}\text { DOI 10.1159/000369673 } \\
\text { Published onlne: January 02, } 2015\end{array}$ & $\begin{array}{l}\text { C) } 2015 \text { S. Karger AG, Basel } \\
\text { www.karger.com/cpb }\end{array}$ \\
\cline { 2 - 3 } &
\end{tabular}}

Fig. 4. (a) The diversity of NO production in different groups. (A) Control, (B) HG, (C) HG+Calindol, (D) HG+Calhex231, (E) HG+L-NMMA, (F) $\mathrm{HG}+\mathrm{CaCl}_{2}$. The quantitation of NO generation for each of the different groups is shown in the lower panel. Values represent group means \pm SEMs. ${ }^{* * *} P<0.001$ vs. Control group; $\S P<0.05$ vs. HG.Scale bar is $100 \mu \mathrm{m}$. (b) The protein levels of p-eNOS in hippocampal neurons were analyzed by Western blot. Basal levels of peNOS were detected in the control group, which served as the baseline for computing the fold increase for the other groups. The quantitation of the Western blot analysis for p-eNOS is shown in the lower panel. The fold change values represent group means \pm SEMs. ${ }^{*} P<0.05$ vs. control; ${ }^{* *} P<0.01$ vs. HG.

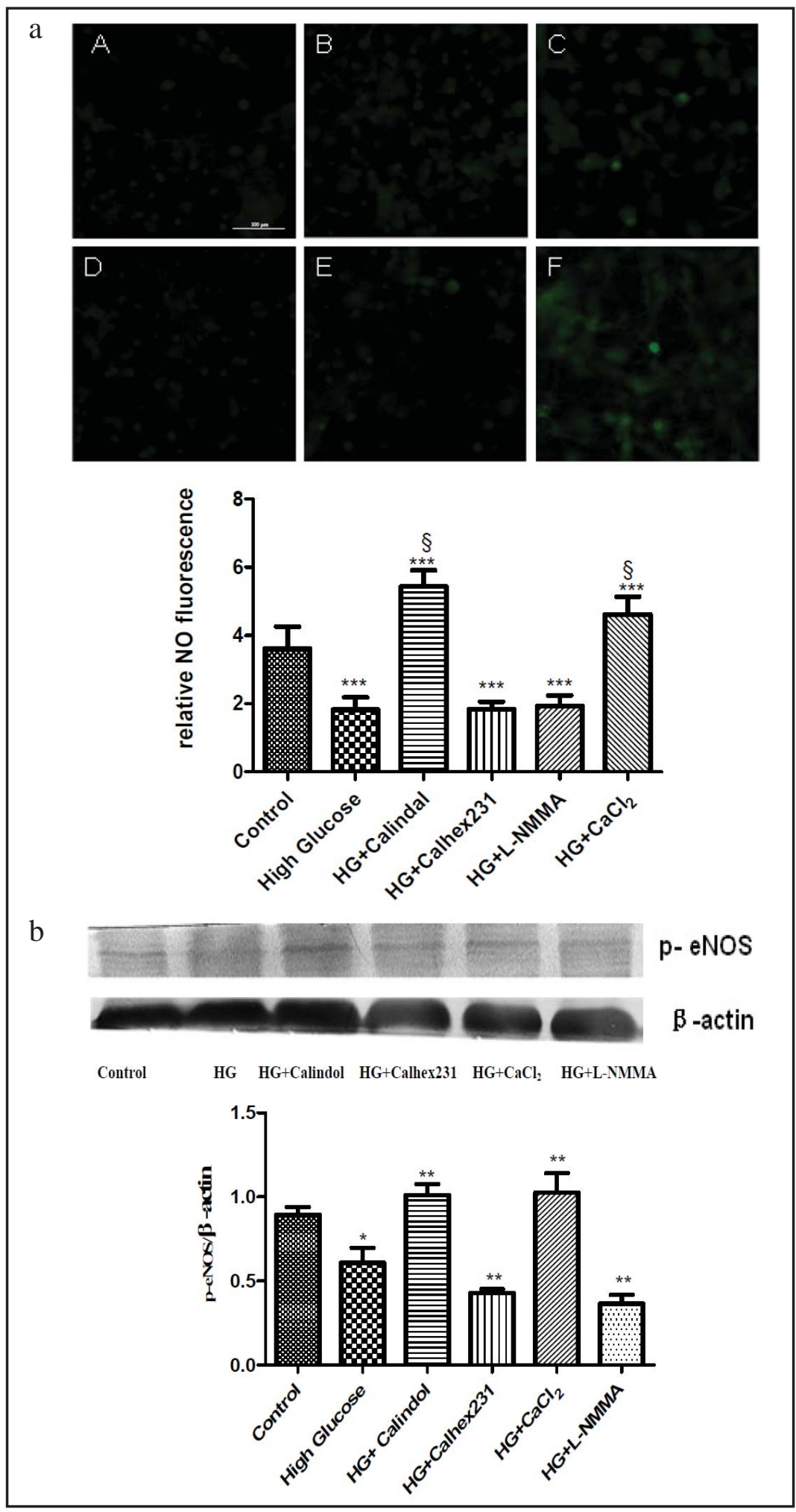

Neurite outgrowth

To investigate the influence of high glucose on the neurite outgrowth of hippocampal neurons, the total neurite length for hippocampal neurons of each condition was analyzed by immunofluorescence labeling for anti-BIII-tubulin. Compared with the control group (3569 $\pm 315.2 \mu \mathrm{m}$ ), the total neurite length in the high glucose (HG) and $\mathrm{HG}+$ Calhex231 groups was 


\section{Cellular Physiology and Biochemistry}

Cell Physiol Biochem 2015;35:38-50

Fig. 5. Total neurite length for rat hippocampal neurons in each condition was detected by immunofluorescence labeling with anti- $\beta$ tubulin III (200X). (A) Control, (B) HG, (C) HG+Calindol, (D) HG+Calhex231. The quantitation of the total neurite length for neurons in each condition is shown in the lower panel. The fold change values represent group means \pm SEMs. ${ }^{*} P<0.05$ vs. control; $\S P<0.05$ vs. HG.Scale bar is $200 \mu \mathrm{m}$.
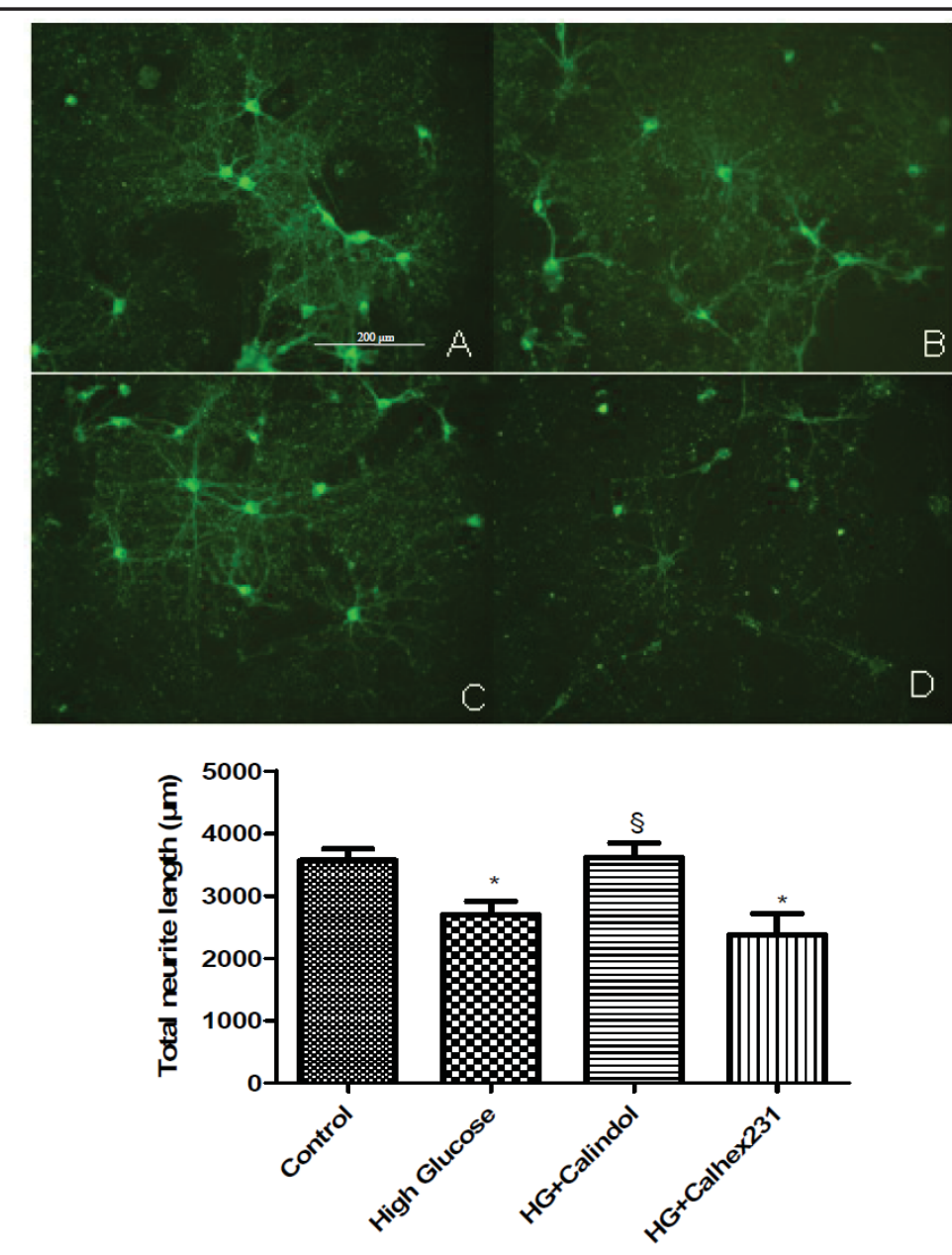

decreased ( $2698 \pm 371 \mu \mathrm{m}$ and $2374 \pm 600 \mu \mathrm{m}$, respectively) compared to the control group $(P<0.05)$, while the $\mathrm{HG}+\mathrm{Calindol}$ group was increased $(3614 \pm 525.2 \mu \mathrm{m})(P<0.05)$. The total neurite length in the $\mathrm{HG}+$ Calindol group was increased relative to the $\mathrm{HG}$ group $(P<0.05)$, while the $\mathrm{HG}+$ Calhex231 group was decreased $(P<0.05)$ (Fig. 5).

\section{The level of ROS measured by MitoSOX Red}

Some studies show that mitochondrial dysfunction and subsequent ROS production are involved in the development of diabetes. Because hyperglycemia is known to disturb mitochondrial function and because mitochondria are likely the major source of ROS, we measured the level of ROS using MitoSOX Red in neonatal rat hippocampal neurons from each group (Fig. 6a). ROS production significantly increased in the HG group compared with the control group $(P<0.001)$. Compared with the HG group, fluorescence intensity of ROS production in the $\mathrm{HG}+$ Calindol, $\mathrm{HG}+$ Calhex231, $\mathrm{HG}+\mathrm{L}-\mathrm{NMMA}$ and $\mathrm{HG}+\mathrm{IBMX}$ groups was clearly decreased $(P<0.05)$.

\section{Measurement of mitochondrial membrane potential by JC-1 staining}

In our study, the mitochondrial membrane potential was detected using a membrane potential-specific dye, JC-1. Healthy non-apoptotic cells maintain a high mitochondrial membrane potential, and exhibits red fluorescence. In contrast, unhealthy, apoptotic cells exhibits green fluorescence. As seen in Fig. 6b, the HG group showed a clearly decreased mitochondrial membrane potentialrelative to control neurons, as observed through changes in the amount of green fluorescence $(P<0.001)$, whereas the $\mathrm{HG}+\mathrm{Calindol}, \mathrm{HG}+\mathrm{L}-\mathrm{NMMA}$ and $\mathrm{CaCl}_{2}$ groups exhibited increased mitochondrial membrane potential compared to the HG group 


\section{Cellular Physiology Cell Physiol Biochem 2015;35:38-50

and Biochemistry \begin{tabular}{l|l}
$\begin{array}{l}\text { DOI: 10.1159/000369673 } \\
\text { Published onine: anuary 02, } 2015\end{array}$ & $\begin{array}{l}\text { O 2015 S Karger AG, Basel } \\
\text { www.karger.com/cpb }\end{array}$ \\
\cline { 2 - 3 }
\end{tabular}

Fig. 6. (a)The diversity of ROS production in mitochondria from different groups. (A) Control, (B) HG, (C) HG+Calindol, (D) $\mathrm{HG}+$ Calhex231, (E) $\mathrm{HG}+\mathrm{L}-$ NMMA, (F) $\mathrm{HG}+\mathrm{CaCl}_{2}$. Quantitative results of MitoSOX Red fluorescence for each of the different groups is shown in the lower panel. Values represent group means \pm SEMs. ${ }^{* * *} P<0.001$ vs. Control; $\S P<0.05$ vs. HG.Scale bar is $200 \mu \mathrm{m}$. (b) The diversity of mitochondrial transmembrane potential in each of the different groups. (A) Control, (B) $\mathrm{HG}$, (C) $\mathrm{HG}+$ Calindol, (D) HG+Calhex231, (E) HG+L-NM$\mathrm{MA},(\mathrm{F}) \mathrm{HG}+\mathrm{CaCl}_{2}$. The quantitation of JC-1 staining for each of the different groups is shown in the lower panel. Values represent group means \pm SEMs. ${ }^{* * *}$ $P<0.001$ vs. Control; $\S P<0.05$ vs. HG.Scale bar is $200 \mu \mathrm{m}$.
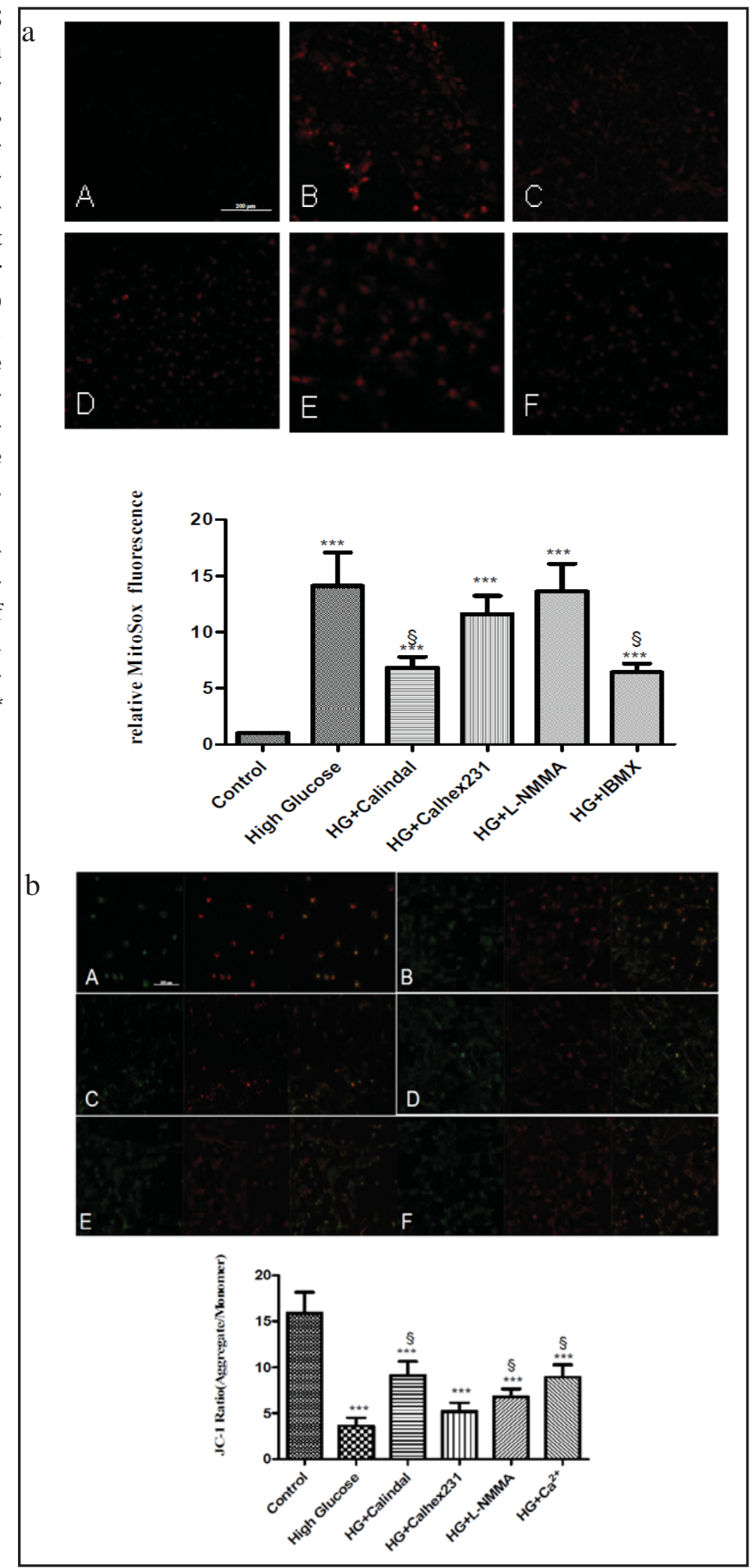

at $30 \mathrm{~min}(P<0.05)$. Because a decrease in mitochondrial membrane potential indicates an early stage of apoptosis, our results suggested that high glucose treatment might result in neuronal apoptosis. However, Calindol treatment attenuated the decrease in mitochondrial membrane potential in neonatal rat hippocampal neurons. 


\section{Cellular Physiology and Biochemistry}

Cell Physiol Biochem 2015;35:38-50

\begin{tabular}{l|l}
\hline DOI: $10.1159 / 000369673$ & C 2015 S. Karger AG, Basel
\end{tabular}

www.karger.com/cpb

\section{Discussion}

Diabetic encephalopathy is a serious DM complication. To explore the molecular mechanisms underlying diabetic encephalopathy, the establishment of a reliable animal model is critical. In this study, intraperitoneal injection of STZ was used to generate a rat diabetes model. Water and food intake and the serum concentration of glucose were significantly increased in diabetic model groups compared to the control group, indicating the successful establishment of the diabetic model. Ultrastructural injuries and the level of apoptosis in diabetic hippocampal neurons corresponded to the characteristics of diabetic encephalopathy.

To investigate the roles of CaSR in the mechanism of diabetic encephalopathy, a cellular diabetes model was established using hippocampal neurons treated with $30 \mathrm{mM}$ glucose. Our results suggested that the expression of CaSR significantly decreased and was accompanied by a decrease in $\left[\mathrm{Ca}^{2+}\right]_{\mathrm{i}}$ in these neurons. CaSR stimulation elicits PLC-mediated IP formation, leading to an elevation in $\left[\mathrm{Ca}^{2+}\right]_{i}[24]$. Down-regulation of CaSR expression was involved in rat diabetic encephalopathy. Calindol, a CaSR agonist, could attenuate the high glucose effects and maintain the status of the cells.

The reduction in the levels of CaSR protein caused disturbances in $\mathrm{Ca}^{2+}$ homeostasis, induced the alteration of a series of downstream signaling pathways, or directly damaged cellular structure through mitochondrial dysfunction. A substantial number of studies have indicated that the destruction of mitochondrial transmembrane potential is one of the earliest events in the apoptotic cascade, as it occurs before the nuclear features of apoptosis become apparent, and once it collapses, cellular damage becomes irreversible. The results of JC-1 staining suggested that the ratio of aggregate/monomer in high glucose-treated cells was markedly decreased, whereas $2 \mu \mathrm{M}$ Calindol and $2.3 \mathrm{mM} \mathrm{CaCl}_{2}$ could stabilize the mitochondrial transmembrane potential.

In recent years, considerable circumstantial evidence has indicated a role for diabetes-induced oxidative stress, which is routinely accompanied by diabetic encephalopathy [25]. Oxidative stress contributes to increased neuronal damage and death through protein oxidation, DNA damage, and peroxidation of membrane lipids [26]. Oxidative stress is thought to play a crucial role in the development of memory impairment in diabetes [27]. The activation of CaSR by Calindol inhibited ROS production in a manner similar to IBMX, an endogenous PDE inhibitor.

CaMKII is regulated by the $\mathrm{Ca}^{2+} /$ calmodulin complex and has been involved in many signaling cascades and is thought to be an important mediator of learning and memory [28]. When there is insufficient calcium or calmodulin present to bind to neighboring subunits, auto-phosphorylation does not occur. As greater amounts of calcium and calmodulin accumulate, auto-phosphorylation occurs, leading to persistent activation of the CaMKII enzyme for a short period of time [29]. KN-93 is an effective inhibitor of CaMKII activity and autophosphorylation of the $\alpha$ - and $\beta$-subunits of CaMKII. In our study, the level of p-CaMKII decreased in neurons treated with high glucose. However, the level of p-CaMKII increased in the $\mathrm{HG}+$ Calindol group and decreased in the $\mathrm{HG}+$ Calhex 231 and $\mathrm{HG}+\mathrm{KN} 93$ groups compared with the HG group, approximating the changes in $\left[\mathrm{Ca}^{2+}\right]_{i}$. The level of total CaMKII in the high glucose-treated neurons was increased compared to the control group, suggesting a compensatory increase in protein synthesis. The levels of p-CaMKII and CaMKII in hippocampal neurons in the $\mathrm{CaCl}_{2}$ group was largely unchanged, suggesting that CaSR may improve the status of neurons treated with high glucose through regulating $\left[\mathrm{Ca}^{2+}\right]_{i}$

Nitric oxide (NO) is found in biological systems following synthesis from the amino acid L-arginine by nitric oxide synthase (NOS). In the brain, in addition to relaxing the cerebral vasculature, NO plays a role as a neurotransmitter. The function of NO in the hypothalamus has been implicated in the learning process and in memory formation [30]. Long-term potentiation (LTP) and long-term depression (LTD) are two major forms of activity-dependent synaptic plasticity in the brain. The NO-cGMP pathway has been implicated in the induction of hippocampal LTP and LTD, which are known to be the predominant mechanisms for learning and memory [31]. 


\section{Cellular Physiology and Biochemistry}

Cell Physiol Biochem 2015;35:38-50

DOI: $10.1159 / 000369673$

Publisnea onime: January 02, 2015

Dong et al.: CaSR in Diabetic Encephalopathy
(C) 2015 S. Karger AG, Basel

www.karger.com/cpb

$\mathrm{Ca}^{2+}$ and calmodulin (CaM) can activate the NOS in the endochylema, which can catalyze the formation of NO. Factors that can elevate $\left[\mathrm{Ca}^{2+}\right]_{i}$ may also activate NOS, but long-lasting increases in $\left[\mathrm{Ca}^{2+}\right]_{\mathrm{i}}$ may down-regulate NO formation, as in vitro phosphorylation by CaMKII decreases the Vmax of NOS. In addition to the conversion of L-arginine, nNOS generates $\mathrm{H}_{2} \mathrm{O}_{2}$ and reduces cytochrome c (P450) in a $\mathrm{Ca}^{2+} /$ calmodulin-dependent manner [32]. In our study, in addition to decreases in NO in the HG group, the levels of p-eNOS were significantly decreased compared with the control group. These results were consistent with a change in the expression of CaSR and $\left[\mathrm{Ca}^{2+}\right]_{i}$. Furthermore, NO and p-eNOS increased upon treatment with Calindol and $\mathrm{CaCl}_{2}$ but decreased with Calhex231 and L-NMMA treatment, suggesting that CaSR promoted the synthesis of NO in the high glucose environment.

In this study, CaSR regulated neurite outgrowth might be related to the levels of $\mathrm{p}$ CaMKII and the production of NO. $\mathrm{CaCl}_{2}$ had two roles: a CaSR agonist and the source of $\left[\mathrm{Ca}^{2+}\right]$ . In hippocampal neurons treated with high glucose, $\mathrm{Ca}^{2+}$ homeostasis was disturbed, but the finding that Calindol treatment was nearly identical to $\mathrm{CaCl}_{2}$ treatment could demonstrate that CaSR might protect hippocampal neurons from the effects of incubation with high glucose through positive compensatory protection to inhibit and delay rat diabetic encephalopathy. Therefore, it may be possible for diabetic patients to use exogenous CaSR agonists such as calcium, magnesium and zinc to ease the symptoms of diabetic encephalopathy.

\section{Acknowledgments}

This study was supported by the National Natural Science Foundation of China (81300164, 81370330 , 81370421 ,81170289, 81170218, 81170178), the Yu Weihan grant for excellent younger scientists of Harbin Medical University (to Weihua Zhang).

\section{Disclosure Statement}

The authors declare no conflict of interest. The authors have not published or submitted the manuscript elsewhere.

\section{References}

1 King H, Aubert RE, Herman WH: Global burden of diabetes 1995-2025: prevalence, numerical estimates, and projections. Diabetes Care 1998;21:1414-1431.

-2 Li J,Zhang S,Zhang L,Wang R,Wang M:Effects of L-3-n-Butylphthalide on Cognitive Dysfunction and NR2B Expression in Hippocampus of Streptozotocin (STZ)-Induced Diabetic Rats. Cell Biochem Biophys DOI: 10.1007/s12013-014-0200-5.

-3 Biessels GL, van der Heide LP, Kamal A, Bleys RL, Gispen WH: Ageing and diabetes: Implications for brain function. Eur J Phamacol 2002;441:1- 4.

- 4 Biessels GJ, Kamal A, Ramakers GM, Urban IJ, Spruijt BM, Erkelens DW, Gispen WH: Place learning and hippocampal synaptic plasticity in streptozotocin-induced diabetic rats. Diabetes 1996;45:1259-1266.

-5 Singhal K, Sandhir R: L-type calcium channel blocker ameliorates diabetic encephalopathy by modulating dysregulated calcium homeostasis. J Neurosci Res DOI: 10.1002/jnr.23478.

6 Ryle C, Leow CK, Donaghy M: Nonenzymatic glycation of peripheral and central nervous system proteins in experimental diabetes mellitus. Muscle Nerve 1997;20:577-584.

7 Rharass T, Lemcke H, Lantow M, Kuznetsov SA, Weiss DG, Panáková Det: $\mathrm{Ca}^{2+}$-mediated Mitochondrial Reactive Oxygen Species Metabolism Augments Wnt/ $\beta$-Catenin Pathway Activation to Facilitate Cell Differentiation. J Biol Chem 2014;289:27937-27951.

8 Komary Z, Tretter L, Adam-Vizi V: H2O2 generation is decreased by calcium in isolated brain mitochondria. Biochim Biophys Acta 2008;1777:800-807.

-9 Ruat M, Molliver ME, Snowman AM, Snyder SH: Calcium sensing receptor: molecular cloning in rat and localization to nerve terminals. Proc Natl Acad Sci U S A 1995;92:3161-3165. 


\section{Cellular Physiology and Biochemistry}

Cell Physiol Biochem 2015;35:38-50

10 Yano S, Brown EM, Chattopadhyay N: Calcium-sensing receptor in the brain. Cell Calcium 2004;35:257264.

-11 Wang R, Xu CQ, Zhao WM, Zhang J, Cao K, Yang B, Wu L: Calcium and polyamine regulated calcium-sensing receptors in cardiac tissues. Eur J Biochem 2003;270:2680-2688.

12 Vizard TN, O'Keeffe GW, Gutierrez H, Kos CH, Riccardi D, Davies AM: Regulation of axonal and dendritic growth by the extracellular calcium-sensing receptor. Nat Neurosci 2008;11:285-291.

13 Ruat M,Traiffort E. Roles of the calcium sensing receptor in the central nervous system. Best Pract Res Clin Endocrinol Metab 2013;27:429-442.

14 Armato U,Bonafini C,Chakravarthy B, Pacchiana R, Chiarini A, Whitfield JF, Dal Prà I: The calcium-sensing receptor: a novel Alzheimer's disease crucial target? J Neurol Sci 2012;322:137-140.

15 Dityateva G, Hammond M, Thiel C, Ruonala MO, Delling M, Siebenkotten G, Nix M, Dityatev A: Rapid and efficient electroporation-based gene transfer into primary dissociated neurons. Neurosci Methods 2003;130:65-73.

16 Redmond L, Kashani AH, Ghosh A: Calcium Regulation of Dendritic Growth via CaM Kinase IV and CREBMediated Transcription. Neuron 2002;34:999-1010.

- 17 Duncan RS, Hwang SY, Koulen P: Differential inositol 1,4,5-trisphosphate receptor signaling in a neuronal cell line. Int J Biochem Cell Biol 2007;39:1852-1862.

18 Fauconnier J, Andersson DC, Zhang SJ, Lanner JT, Wibom R, Katz A, Bruton JD, Westerblad H: Effects of palmitate on $\mathrm{Ca} 2+$ handling in adult control and ob/ob cardiomyocytes: impact of mitochondrial reactive oxygen species. Diabetes 2007;56:1136-1142.

19 Kojima H, Urano Y, Kikuchi K, Higuchi T, Hirata Y, Nagano T: Fluorescent indicators for imaging nitric oxide production. Angew Chem Int Ed Engl 1999;38:3209-3212.

20 Mudo G, Trovato-Salinaro A, Barresi V, Belluardo N, Condorelli DF: Identification of calcium sensing receptor (CaSR) mRNA-expressing cells in normal and injured rat brain. Brain Res 2009;1298:24-36.

21 Maier LS, Bers DM: Calcium, calmodulin, and calcium-calmodulin kinase II: heartbeat to heartbeat and beyond. J. Mol.Cell Cardiol 2002;34:919-939.

22 Nikonenko I, Boda B, Steen S, Knott G, Welker E, Muller D: PSD-95 promotes synaptogenesis and multiinnervated spine formation through nitric oxide signaling. J. Cell Biol 2008;183:1115-1127.

23 Shelly M, Lim BK, Cancedda L, Heilshorn SC, Gao H, Poo MM: Local and long-range reciprocal regulation of cAMP and cGMP in axon/dendrite formation. Science 2010;327:547-552.

24 Lu FH, Fu SB, Leng XN, Zhang X, Dong S, Zhao YJ, Ren H, Li H, Zhong X, Xu CQ, Zhang WH: Role of the Calcium-Sensing Receptor in Cardiomyocyte Apoptosis via the Sarcoplasmic Reticulum and Mitochondrial Death Pathway in Cardiac Hypertrophy and Heart Failure. Cell Physiol Biochem 2013;31:728-743.

25 Fukui K, Omoi NO, Hayasaka T, Shinnkai T, Suzuki S, Abe K, Urano S: Cognitive impairment of rats caused by oxidative stress and aging, and its prevention by vitamin E. Ann N Y Acad Sci 2002;959:275-284.

-26 Hawkins CL, Davies MJ: Generation and propagation of radical reactions on proteins. Biochim Biophys Acta 2001;1504:196-219.

-27 Kucukatay V, Agar A, Gumuslu S, Yargicoglu P: Effect of sulfur dioxide on active and passive avoidance in experimental diabetes mellitus: relation to oxidant stress and antioxidant enzymes. Int J Neurosci 2007;117:1091-1107.

-28 Shonesy BC,Jalan-Sakrikar N,Cavener VS,Colbran RJ: CaMKII: a molecular substrate for synaptic plasticity and memory. Prog Mol Biol Transl Sci 2014;122:61-87.

29 Lisman J: The CaM kinase II hypothesis for the storage of synaptic memory. Trends in neurosciences 1994;17:406-412.

-30 Steinert JR,Chernova T,Forsythe ID: Nitric oxide signaling in brain function, dysfunction, and dementia. Neuroscientist 2010;16:435-452.

-31 Izumi Y, O'Dell KA,Zorumski CF: Metaplasti LTP inhibition after LTD induction in CA1 hippocampal slices involves NMDA Receptor-mediated Neurosteroidogenesis. Physiol Rep DOI: 10.1002/phy2.133.

-32 Song T,Hatano N,Horii M, Tokumitsu H, Yamaguchi F, Tokuda M, Watanabe Y: Calcium/calmodulin-dependent protein kinase I inhibits neuronal nitric-oxide synthase activity through serine 741 phosphorylation. FEBS Lett 2004;570:133-137. 